\title{
A new and efficient methodology for olefin epoxidation catalyzed by supported cobalt nanoparticles
}

\author{
Lucía Rossi-Fernández, Viviana Dorn and Gabriel Radivoy*
}

\author{
Full Research Paper \\ Address: \\ INQUISUR-CONICET, Departamento de Química, Universidad \\ Nacional del Sur, Avenida Alem 1253, Bahía Blanca, B8000CPB, \\ Argentina \\ Email: \\ Gabriel Radivoy* - gradivoy@criba.edu.ar \\ * Corresponding author \\ Keywords: \\ alkenes; cobalt nanoparticles; epoxides; oxidation; TBHP
}

Beilstein J. Org. Chem. 2021, 17, 519-526.

https://doi.org/10.3762/bjoc. 17.46

Received: 16 December 2020

Accepted: 10 February 2021

Published: 22 February 2021

Associate Editor: C. Stephenson

(C) 2021 Rossi-Fernández et al.; licensee Beilstein-Institut. License and terms: see end of document.

\begin{abstract}
A new heterogeneous catalytic system consisting of cobalt nanoparticles (CoNPs) supported on MgO and tert-butyl hydroperoxide (TBHP) as oxidant is presented. This CoNPs@MgO/t-BuOOH catalytic combination allowed the epoxidation of a variety of olefins with good to excellent yield and high selectivity. The catalyst preparation is simple and straightforward from commercially available starting materials and it could be recovered and reused maintaining its unaltered high activity.
\end{abstract}

\section{Introduction}

Olefin oxidation reactions are key synthetic transformations in the production of oxygenated chemicals of high interest for both academic and industrial applications [1]. Among them, allylic oxidation and olefin epoxidation constitute fundamental tools for the synthesis of homoallylic alcohols or $\alpha, \beta$-unsaturated carbonyl compounds, and epoxides, respectively. In particular, epoxides are pivotal building blocks for the synthetic chemists because they are present in many important (bio)organic compounds and also allow access to more functionalized or complex structures through different chemical transformations on the reactive oxirane ring [2-12].

Despite many methodologies for the synthesis of epoxides have been reported, efficient and selective epoxidation of olefins remains a challenge. Due to safety and environmental issues, traditional methods involving the use of stoichiometric amounts of harmful oxidants (for example, peroxosulfates [13] or organic peracids [14]) have been replaced by the use of greener oxidizing agents as molecular oxygen, hydrogen peroxide or tert-butyl hydroperoxide (TBHP) [14-17]. However, using any of these oxidants alone results in considerable low reactivity and selectivity in olefin epoxidation reactions. Thus, several transition-metal-based catalytic methods have been developed, most of them using expensive or scarce metals (Au or Pd [18$21]$, groups IV and V metal oxides [22,23]) and mainly through homogeneous catalytic processes [24-26]. From a practical, economic and environmental point of view, reusable heterogeneous catalysts based on earth-abundant transition metals are much more attractive, especially for industrial applications $[27,28]$. 
In recent years, many efforts have been made in finding new catalytic systems based on the use of low cost and abundant non-noble metals, and much attention have been paid to the development of $\mathrm{Fe}, \mathrm{Mn}$ and mainly Co-based catalysts for olefin epoxidation. Besides their low cost and low toxicity, the choice of these metals is related to their known ability to activate dioxygen in natural processes catalyzed by metal-containing enzymes [29,30]. Despite that various homogeneous [31,32] and heterogeneous [33-37] Co-based catalysts have been applied to the epoxidation of alkenes, however, most of the reported methods lead to unsatisfactory yield, low selectivity, or limited substrate scope. Suib et al. [38] reported on the synthesis of mesoporous $\mathrm{Co}_{3} \mathrm{O}_{4}$ for the catalytic epoxidation of a variety of alkenes as an interesting heterogeneous system. This cobalt oxide mesoporous nanomaterial showed good activity and selectivity to the epoxide product and could be recovered and reused, but the multistep (not straightforward) synthesis of the catalyst and the use of DMF as the solvent $\left(\right.$ at $100^{\circ} \mathrm{C}$ ) are main drawbacks of this methodology. DMF has been the solvent of choice in most cobalt-based epoxidation systems and it has been proposed that this solvent could serve as oxygen-transfer agent but, at the same time, could lead to considerable amounts of formamide byproducts $[39,40]$.

On the other hand, the use of supported cobalt nanoparticles as efficient catalysts for the epoxidation of olefins has received increasing attention in the last years. In most cases, a crucial influence of the support $\left(\mathrm{TiO}_{2}, \mathrm{HAP}, \mathrm{CNTs}, \mathrm{SBA}, \mathrm{SiO}_{2}\right)$, the oxidant agent (molecular oxygen or TBHP) and the solvent (DMF, MeCN, ethyl acetate, DMSO, solvent free) on the activity and selectivity of the nanocatalysts has been noted [27,4144].

Furthermore, all the reported methodologies use either molecular oxygen together with an aldehyde as a co-reductant, or only a "green" peroxide $\left(\mathrm{H}_{2} \mathrm{O}_{2}\right.$, TBHP) as the oxidant agent. Among the reported methods that make use of peroxides as oxidants, cobalt nanoparticles supported on CNTs together with TBHP as oxidant for the epoxidation of styrene, gave good selectivity to styrene oxide but conversions were lower than $40 \%$ [41]. More recently, Hutchings et al. reported on a $\mathrm{Co}_{3} \mathrm{O}_{4} / \mathrm{TiO}_{2}$-catalyzed solvent-free version that allowed the use of molecular oxygen together with sub-stoichiometric amounts of TBHP as radical initiator at $80{ }^{\circ} \mathrm{C}$, with conversions lower than $40 \%$ and ca. $20 \%$ selectivity in the epoxidation of 1-decene as the only substrate tested [42]. On the other hand, among the peroxide-free oxidation processes, a $\mathrm{Co}_{3} \mathrm{O}_{4} / \mathrm{SBA}-16$ catalyst for the epoxidation of limonene in AcOEt [43] and a Co/HAP catalyst in DCM as the solvent [44] have been very recently reported. Both of these catalytic systems gave good conversions to the desired epoxides and allowed the use of molecular oxygen as oxidant but require the use of high amounts (400-500\% excess) of isobutyraldehyde as co-reductant.

Therefore, there remains a need to develop and improve catalytic systems for alkene epoxidation by using low cost and easy to prepare supported cobalt nanoparticles as reusable heterogeneous catalysts [27] that are wide in substrate scope, active enough and highly selective. As part of our continuing interest in the development of new synthetic methodologies based on the use of catalysis by non-noble transition metal nanoparticles (MNPs) for their application in a wide range of relevant organic transformations [45-52], we report herein our study on the performance of CoNPs/MgO nanocatalyst for olefin epoxidation reactions. Compared to previous reports in the same field, it should be highlighted that our CoNPs/MgO catalyst is readily prepared from low-cost commercially available starting materials, works in acetonitrile as the solvent (thus avoiding the use of toxic DMF), and can be recovered and reused maintaining its high activity.

\section{Results and Discussion}

The supported cobalt nanoparticles tested as catalysts were prepared by fast reduction of anhydrous cobalt(II) chloride with an excess of lithium sand and a catalytic amount of 4,4'-di-tertbutylbiphenyl (DTBB, $10 \mathrm{~mol} \%$ ) as electron carrier, in THF as the solvent. Once the reaction mixture turned to black, indicating the formation of the CoNPs, the corresponding support was added and the resulting suspension was stirred for $2 \mathrm{~h}$ (see Experimental for details). The CoNPs-based catalysts were ready for use after filtration and drying in an oven at $150{ }^{\circ} \mathrm{C}$ for $1 \mathrm{~h}$.

Styrene (1a) was chosen as model substrate for testing the activity and selectivity of a variety of CoNPs-based catalysts (Table 1). The catalytic tests were carried out in a sealed glass tube, under a variety of reaction conditions. We started our study by working in DMF as the solvent, under $\mathrm{O}_{2}(1 \mathrm{~atm}$, balloon) and in the absence of any other oxidant additive. Under these conditions, none of the tested catalysts gave satisfactory results (Table 1, entries 1-4), only the CoNPs/MgO catalyst gave a modest $28 \%$ conversion to the desired epoxide $\mathbf{2 a}$ (Table 1, entry 2) together with undesired formamide byproducts, probably coming from DMF decomposition under the reaction conditions. Then, we decided to use acetontrile ( $\mathrm{MeCN}$ ) as the solvent with the CuNPs supported on $\mathrm{MgO}$ as catalyst, but a similar result to that obtained in DMF was observed (Table 1 , entry 5). The use of $\mathrm{H}_{2} \mathrm{O}_{2}$ as co-oxidant improved the conversion of the starting styrene (1a) only for the CoNPs/MgO catalyst, but lead to low selectivity due to the formation of benzaldehyde and benzylic alcohol byproducts (Table 1, entries 6-9). In view of these results, we decided to continue the optimization of the reaction conditions by testing 
Table 1: Optimization of reaction conditions for the epoxidation of styrene (1a). ${ }^{a}$

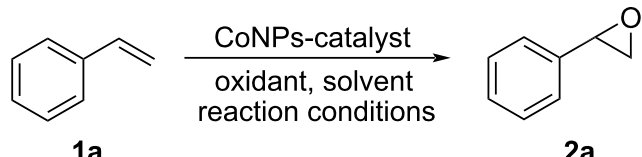

1a

$2 a$

\begin{tabular}{|c|c|c|c|c|c|}
\hline Entry & Catalyst & Solvent & Oxidant & Conversion ${ }^{\mathrm{b}}(\%)$ & Selectivity $^{\mathrm{c}}(\%)$ \\
\hline 1 & CoNPs/ZnO & DMF & $\mathrm{O}_{2}$ & 8 & 30 \\
\hline 2 & CoNPs/MgO & DMF & $\mathrm{O}_{2}$ & 28 & 40 \\
\hline 3 & CoNPs/Celite & DMF & $\mathrm{O}_{2}$ & 0 & - \\
\hline 4 & $\mathrm{CoNPs} / \mathrm{CeO}_{2}$ & DMF & $\mathrm{O}_{2}$ & 0 & - \\
\hline 5 & CoNPs/MgO & $\mathrm{MeCN}$ & $\mathrm{O}_{2}$ & 22 & 35 \\
\hline 6 & CoNPs/ZnO & $\mathrm{MeCN}$ & $\mathrm{H}_{2} \mathrm{O}_{2}$ & 10 & 50 \\
\hline 7 & CoNPs/MgO & $\mathrm{MeCN}$ & $\mathrm{H}_{2} \mathrm{O}_{2}$ & 35 & 45 \\
\hline 8 & CoNPs/Celite & $\mathrm{MeCN}$ & $\mathrm{H}_{2} \mathrm{O}_{2}$ & 0 & - \\
\hline 9 & $\mathrm{CoNPs} / \mathrm{CeO}_{2}$ & $\mathrm{MeCN}$ & $\mathrm{H}_{2} \mathrm{O}_{2}$ & 5 & ND \\
\hline 10 & CoNPs/MgO & $\mathrm{MeCN}$ & TBHP & 64 & 94 \\
\hline 11 & CoNPs/MgO & $\mathrm{DCM}$ & TBHP & 11 & 43 \\
\hline 12 & CoNPs/MgO & $\mathrm{H}_{2} \mathrm{O}$ & TBHP & 15 & 72 \\
\hline 13 & CoNPs/MgO & $\mathrm{MeCN}$ & TBHP & $60^{d} / 95^{e} / 73^{f}$ & 94 \\
\hline
\end{tabular}

aStyrene (1a, $0.5 \mathrm{mmol}$ ), $50 \mathrm{mg}$ of catalyst in $5 \mathrm{~mL}$ of solvent at reflux temperature, $12 \mathrm{~h}$; b ${ }^{\mathrm{G}}$ LC yield based on the starting styrene (anisole as internal standard); ' selectivity expressed as yield of styrene oxide based on the starting styrene; ${ }^{d}$ reaction performed using 5 mg of catalyst, $93 \%$ selectivity; ${ }^{e}$ reaction performed using $10 \mathrm{mg}$ of catalyst, $94 \%$ selectivity; ${ }^{f}$ reaction performed using $20 \mathrm{mg}$ of catalyst, $91 \%$ selectivity.

other oxidizing agents and solvents but only for the CoNPs/ $\mathrm{MgO}$ catalyst. Thus, we found that using this catalyst, in refluxing $\mathrm{MeCN}$ as the solvent and TBHP as oxidant (1 equiv in relation to 1a), resulted in a much better epoxidation system, leading to a $64 \%$ conversion with a highly improved selectivity towards the styrene oxide product $\mathbf{2 a}$ (Table 1, entry 10). Under the same reaction conditions, other solvents such as water or dichloromethane gave poorer conversions and selectivities (Table 1, entries 11 and 12).

Next, we worked on the optimization of the catalyst loading. Thus, when the amount of catalyst was decreased from $50 \mathrm{mg}$ to $20 \mathrm{mg}$, a higher conversion was observed along with a slight drop in the selectivity towards the epoxide product 2a (Table 1, entry 13 , footnote $\mathrm{f}$ ). In view of this observation, we then tested the epoxidation reaction by lowering the catalyst loading. As shown in Table 1 (entry 13, footnote e), the optimum amount of catalyst was found to be $10 \mathrm{mg}$, which corresponds to a cobalt loading of $1.07 \mathrm{~mol} \%$ in relation to the starting styrene (1a), leading to a $95 \%$ conversion with excellent selectivity to the styrene oxide product (2a).

Additional experiments confirmed the need for the presence of both the CoNPs/MgO catalyst and TBHP as oxidant for the selective epoxidation of styrene (1a). Thus, when the reaction was performed without the addition of TBHP, only a $14 \%$ conversion to styrene oxide (2a) was observed, whereas in the absence of the CoNPs $/ \mathrm{MgO}$ catalyst the reaction provided a $36 \%$ conversion into a 1:1 mixture of styrene oxide (2a) and benzaldehyde.

The scope of the method was then analyzed by studying the epoxidation of a variety of alkenes under the optimized conditions. As shown in Table 2, the CoNPs/MgO catalyst proved to be very efficient in the epoxidation of different terminal and internal alkenes, both alkyl- or aryl-substituted ones. Unfortunately, electron-poor olefins, conjugated with $\mathrm{C}=\mathrm{O}$ groups, gave very low conversion (pulegone, $22 \%$ ) or did not react under the optimized conditions, even after $24 \mathrm{~h}$ of reaction time (methyl cinnamate, methyl acrylate, methyl methacrylate, isobutyl acrylate).

For cycloalkenes (Table 2, entries 10-12) different oxidation patterns were observed depending on the alkene structure and/or degree of substitution at the $\mathrm{C}=\mathrm{C}$ double bond. Thus, 1-phenyl-

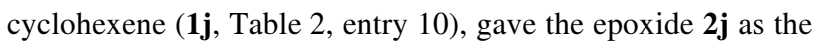
main product along with $19 \%$ of the corresponding allylic ketone in position 3 of the cyclohexenyl moiety ( $\alpha$-oxidation product). On the other hand, the epoxidation of the diene $( \pm)$-limonene (1k, Table 2 , entry 11$)$ took place mainly on the 
Table 2: Epoxidation of various alkenes under the optimized conditions. ${ }^{\text {a }}$

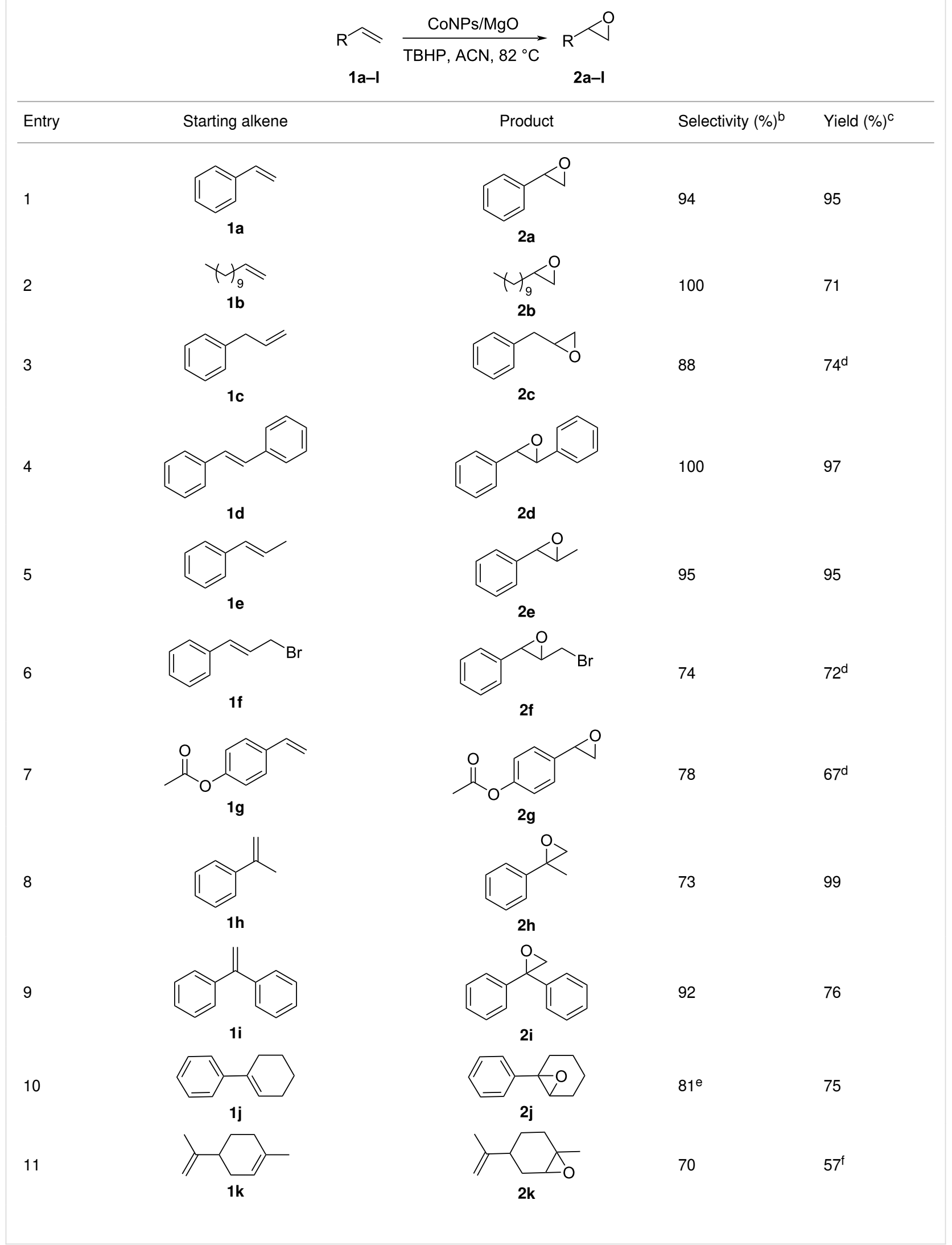


Table 2: Epoxidation of various alkenes under the optimized conditions. ${ }^{a}$ (continued)

12

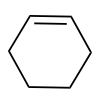

11

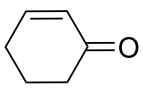

2)
86

90

aAlkene $(0.5 \mathrm{mmol})$, CoNPs/MgO catalyst $(10 \mathrm{mg}, 1.07 \mathrm{~mol} \% \mathrm{Co})$, TBHP $(0.5 \mathrm{mmol})$, in MeCN $(5 \mathrm{~mL})$ at $82{ }^{\circ} \mathrm{C}$ for $12 \mathrm{~h}$, unless otherwise stated; ${ }^{b}$ selectivity expressed as yield of alkene oxide based on the starting alkene determined by GC-MS; ' $G L C$ yield based on the starting styrene (anisole

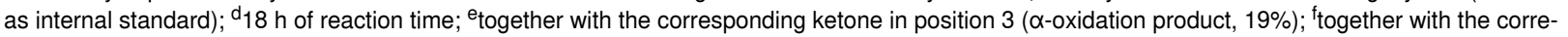
sponding diepoxide as byproduct (10\%).

endocyclic $\mathrm{C}=\mathrm{C}$ double bond with good selectivity, although with a relatively modest conversion. On the contrary, for cyclohexene (11, Table 2, entry 12) the main oxidation product was found to be the corresponding allylic ketone $2 \mathbf{l}$ coming from the $\alpha$-oxidation of the starting alkene. It is known that the product selectivity in the oxidation of cyclohexene could be influenced by the catalyst and reaction conditions (solvent, temperature, catalyst loading, oxidant) [14].

Based on our experimental observations and those previously made by other authors [15-17,41-44], we assumed that a radical oxidation process could be taking place. To test this assumption, the epoxidation of styrene was carried out under the optimized conditions by adding hydroquinone ( $5 \mathrm{mg}, 0.045 \mathrm{mmol}$ ) as radical scavenger. After $8 \mathrm{~h}$ of reaction time only $9 \%$ conversion into styrene oxide (2a) was observed, thus evidencing the presence of radical species as reaction intermediates.

The reusability of the CoNPs/MgO catalyst was then studied for styrene (1a) epoxidation as model reaction. After each cycle, the catalyst was separated from the reaction medium by centrifugation and washed several times with acetonitrile. Thus, the catalyst could be recovered and reused in three consecutive cycles, showing no loss of activity, but a drop in selectivity after the first cycle (selectivity/conversion for each cycle: 94/99.5; 78/99; 77/99). The origin of the observed loss in selec- tivity is difficult to ascertain at this stage, but we think that it could be related to the strong adsorption of some of the reaction products on the catalyst surface. In fact, FTIR analysis of the spent catalyst, after washing it three times with the reaction solvent, showed a weak band at near $1610 \mathrm{~cm}^{-1}$ which could be assigned to the presence of benzaldehyde surface species [53] that could be affecting to some extent the selectivity of the catalyst.

The heterogeneous nature of the catalytic process was confirmed by a hot filtration test. For this purpose, under the optimized conditions the epoxidation of styrene (1a) was stopped at $20 \%$ conversion ( $20 \mathrm{~min}$ ), the catalyst filtered off and the resulting filtrate was allowed to react for 6 additional hours. Analysis by $\mathrm{GC}-\mathrm{MS}$ of the crude reaction mixture revealed a conversion of only $33 \%$ into styrene oxide (2a), thus confirming the heterogeneous nature of the catalytic method.

The freshly prepared CoNPs/MgO catalyst was characterized by means of transmission electron microscopy (TEM), energy dispersive X-ray spectroscopy (EDX), inductively coupled plasma atomic emission spectroscopy (ICP-AES), X-ray diffraction (XRD) and X-ray photoelectron spectroscopy (XPS) (see Supporting Information File 1). TEM analysis showed the presence of highly dispersed spherical cobalt nanoparticles, most of them ranging between 6 and $11 \mathrm{~nm}$ in size (Figure 1).
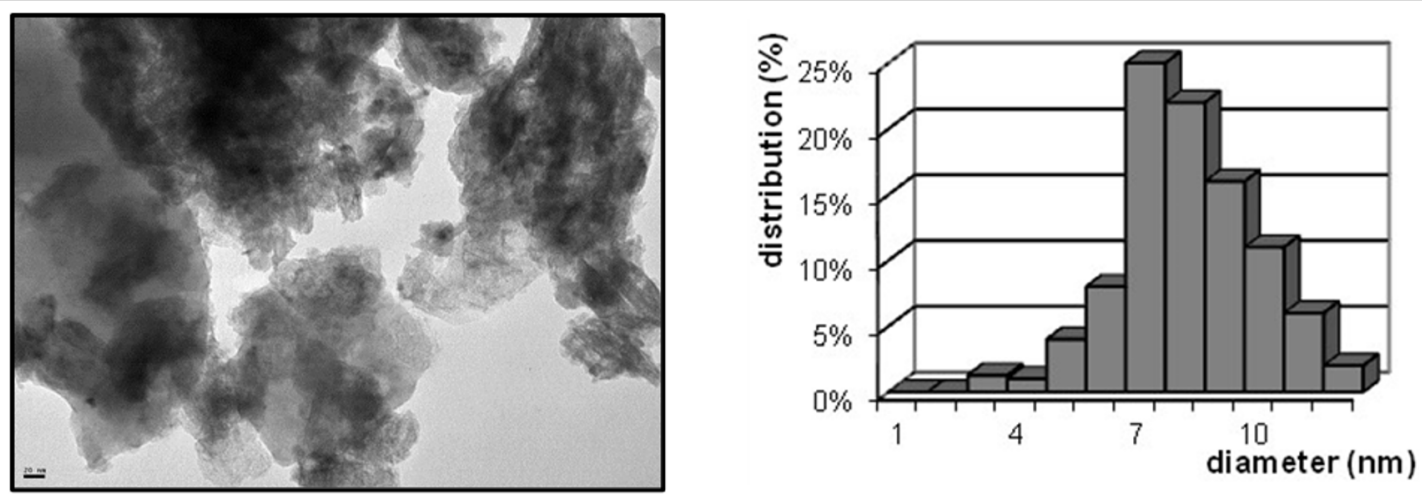

Figure 1: TEM micrograph and size distribution graphic for CoNPs@MgO catalyst (scale bar = 20 nm). 
EDX analysis in various regions of the sample (Figure S2, Supporting Information File 1) confirmed the presence of cobalt with energy bands of 0.8 (L line), 6.9 and $7.7 \mathrm{keV}$ (K lines). The XRD diffractogram showed only the support diffraction pattern, no diffraction peaks owing to cobalt species could be observed. The cobalt loading fixed to the $\mathrm{MgO}$ support was $1.9 \mathrm{wt} \%$ as determined by ICP-AES. The analysis of the XPS spectra in the Co $2 p$ region was consistent with the presence of $\mathrm{Co}^{2+}$ and $\mathrm{Co}^{3+}$, with main binding energy peaks at 779.6 and $780.0 \mathrm{eV}$, along with satellite signal at approximately $786 \mathrm{eV}$, which in principle could be ascribed to $\mathrm{Co}_{3} \mathrm{O}_{4}$ species in the catalyst (Figure S4, Supporting Information File 1). Nevertheless, it must be pointed out that the oxidation state of cobalt is difficult to assign from the XPS results, due to the binding energy overlap of the different cobalt oxides [54].

Based on our results and previous reports by other groups on the same area, we proposed a plausible mechanistic pathway involving a $\mathrm{Co}(\mathrm{II}) / \mathrm{Co}(\mathrm{III})$ couple species, as depicted in Scheme 1 . We assume that tert-butyl hydroperoxide could react with $\mathrm{Co}$ (II) species on the surface of the catalyst leading to the formation of metal-oxy radical $\mathbf{A}$. This intermediate could react with the olefin to give $\pi$-bonded species of type $\mathbf{B}$ which could then lead to the formation of the corresponding epoxide product via the metalloepoxi species $\mathbf{C}[55,56]$. On the other hand, considering that the reaction is carried out under air atmosphere, and that in the absence of TBHP the epoxidation also takes place to some extent, we assume that a competitive reaction pathway involving the participation of cobalt-superoxo active radicals $(\mathrm{Co}-\mathrm{O}-\mathrm{O} \bullet)$ generated by interaction of the CoNPs with $\mathrm{O}_{2}[15]$ could not be disregarded.

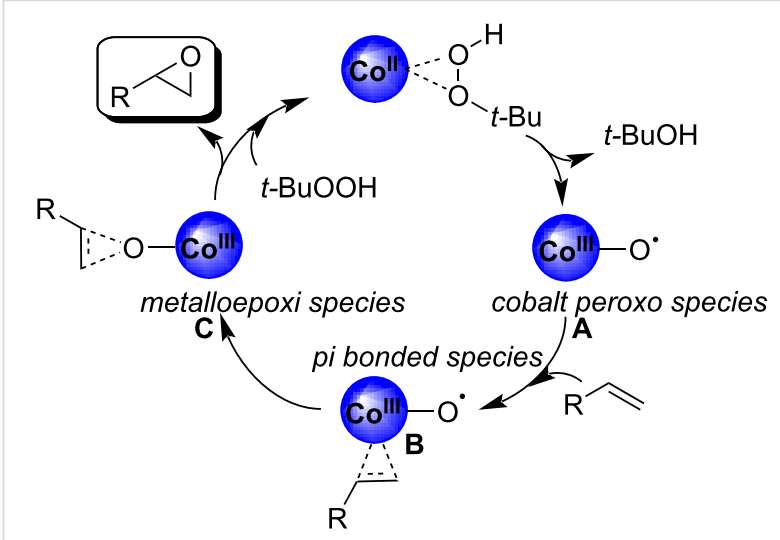

Scheme 1: Plausible mechanistic pathway for olefin epoxidation catalyzed by $\mathrm{CoNPs} / \mathrm{MgO}$ in the presence of $t-\mathrm{BuOOH}$.

\section{Conclusion}

To conclude, we have described a new and efficient heterogeneous CoNPs@MgO catalyst that, in combination with TBHP as oxidant, selectively oxidizes terminal and internal alkenes to the corresponding epoxides in good to excellent yields. The catalyst is readily prepared from commercial starting materials and can be recovered and reused without significant loss of activity. Based on our experimental observations and previously reported studies on cobalt-based alkene epoxidation catalytic systems, a plausible mechanistic pathway involving metal-oxy radical species has been proposed.

\section{Experimental}

All starting materials were of the highest available grade (Aldrich, Fluka, Merck) and were used without further purification. Commercially available cobalt(II) chloride hexahydrate was dehydrated upon heating under vacuum $\left(150{ }^{\circ} \mathrm{C}\right.$, $1.0 \mathrm{mmHg}, 45 \mathrm{~min}$ ) prior to use for the preparation of CoNPs. Column chromatography was performed with Merck silica gel 60 (0.040-0.063 $\mu \mathrm{m}, 240-400 \mathrm{mesh})$. Thin-layer chromatography (TLC) was performed on precoated silica gel plates (Merck $\left.60, \mathrm{~F}_{254}, 0.25 \mathrm{~mm}\right)$.

\section{Instrumentation and analysis}

Nuclear magnetic resonance (NMR) spectra were recorded on a Bruker ARX-300 spectrophotometer using $\mathrm{CDCl}_{3}$ as the solvent and tetramethylsilane (TMS) as internal reference. Mass spectra (EI) were obtained at $70 \mathrm{eV}$ on a Agilent HP-7890B GC/MS instrument equipped with a Agilent 5977A selective mass detector. Infrared (FTIR) spectra were obtained on a Nicolet-Nexus spectrophotometer. The purity of volatile compounds and the chromatographic analyses (GC) were determined with a Shimadzu GC-14B instrument equipped with a flame-ionisation detector and a $30 \mathrm{~m}$ column (HP-5MS, $0.25 \mathrm{~mm}, 0.25 \mu \mathrm{m}$ ), using nitrogen as carrier gas.

\section{Catalyst characterization}

The freshly prepared catalyst was characterized by transmission electron microscopy (TEM) in a JEOL 100CX2 instrument, operated at an acceleration voltage of $100 \mathrm{kV}$. Approximately one hundred metal particles were measured to perform the particle size distribution. The cobalt content in the supported catalyst was determined by inductively coupled plasma atomic emission spectroscopy (ICP-AES), on a Spectro Arcos instrument. X-ray diffraction (XRD) analyses were performed using a Bruker AXS D8 Advance diffractometer, equipped with a $\mathrm{Cu}-\mathrm{K} \alpha 1,2$ radiation source. Atomic absorption spectroscopy was carried out on a Perkin Elmer AAnalist200 spectrometer. $\mathrm{X}$-ray photoelectron spectroscopic analyses (XPS) were performed on a PHI 548 spectrometer, using $\mathrm{Mg} \mathrm{K} \alpha$ radiation at $250 \mathrm{~W}$ and $20 \mathrm{~mA}$. The resolution spectra were taken at $50 \mathrm{eV}$ of pass energy, giving an absolute resolution of $\pm 0.5 \mathrm{eV}$. The operation base pressure was kept in $10^{-10}$ Torr range. The 
adventitious $\mathrm{C}$ 1s binding energy was taken as a charge reference and fixed at $284.8 \mathrm{eV}$.

\section{Catalysts preparation - general procedure}

Analogous as described in [57], a mixture of lithium sand (21 mg, $3.0 \mathrm{mmol}$ ) and 4,4'-di-tert-butylbiphenyl as electron carrier (DTBB, $26 \mathrm{mg}, 0.1 \mathrm{mmol}$ ) was placed in a pre-dried Schlenk-type reaction vessel under nitrogen atmosphere. Then anhydrous THF ( $3 \mathrm{~mL}$ ) was added and the reaction mixture was stirred at room temperature until it turned dark green (5-10 min), indicating the formation of the corresponding lithium arenide. Anhydrous cobalt(II) chloride was then added (130 $\mathrm{mg}, 1.0 \mathrm{mmol})$ and the resulting suspension was stirred until it turned black (15-30 min), indicating the formation of cobalt nanoparticles. Then, it was diluted with THF $(10 \mathrm{~mL})$ and $800 \mathrm{mg}$ of the corresponding support $\left(\mathrm{MgO}, \mathrm{ZnO}, \mathrm{CeO}_{2}\right.$, Celite) were added. The resulting suspension was stirred for $1 \mathrm{~h}$, and then bidistilled water $(2 \mathrm{~mL})$ was added for eliminating the excess of lithium. The resulting solid was filtered under vacuum in a Büchner funnel and washed successively with water $(10 \mathrm{~mL})$ and acetone $(10 \mathrm{~mL})$. Finally, the solid was dried under vacuum (5 Torr).

\section{Catalytic test - typical procedure for olefin epoxidation}

To a vigorously stirred suspension of the $\mathrm{CoNPs} / \mathrm{MgO}$ catalyst $(10 \mathrm{mg})$ and TBHP $(63 \mu \mathrm{L}$ of an $80 \mathrm{wt} \%$ solution in water, $0.5 \mathrm{mmol})$ in acetonitrile $(5 \mathrm{~mL})$, the corresponding alkene $(0.5 \mathrm{mmol})$ was added. The reaction flask was sealed with a screw cap and introduced in a preheated silicon oil bath at a temperature high enough to ensure the reflux of the solvent $\left(82{ }^{\circ} \mathrm{C}\right)$, and stirred at this temperature until total conversion of the starting alkene (TLC, GC). Then, the reaction mixture was centrifuged and the supernatant removed. The solvent was evaporated in vacuo, and the crude product was purified by flash column chromatography (silica gel, hexane/ AcOEt). The recovered solid catalyst was washed with acetonitrile $(3 \times 2 \mathrm{~mL})$ and dried in an oven $\left(150{ }^{\circ} \mathrm{C}, 1 \mathrm{~h}\right)$ for its reuse.

\section{Supporting Information}

\section{Supporting Information File 1}

Detailed experimental procedures, product characterization data, copies of ${ }^{1} \mathrm{H}$ and ${ }^{13} \mathrm{C}$ NMR spectra of selected epoxides and full characterization of the CuNPs/MgO catalyst.

[https://www.beilstein-journals.org/bjoc/content/ supplementary/1860-5397-17-46-S1.pdf]

\section{Acknowledgements}

The authors thank Dr. Fernando Prado and Dr. Miguel Sanchez from IFISUR, CONICET-UNS, for XRD and XPS analyses, respectively.

\section{Funding}

This work was generously supported by the Consejo Nacional de Investigaciones Científicas y Técnicas (CONICET, PIP2011-11220100100268), Agencia Nacional de Promoción Científica y Tecnológica (ANPCyT, Prest. BID, PICT-20142171) and Universidad Nacional del Sur (UNS, PGI 24/Q072) from Argentina. L.R.F. thanks the CONICET for a doctoral fellowship.

\section{ORCID ${ }^{\circledR}$ iDs}

Viviana Dorn - https://orcid.org/0000-0001-8947-0049

Gabriel Radivoy - https://orcid.org/0000-0001-7538-2267

\section{References}

1. Centi, G.; Cavani, F.; Trifiro, F. Trends and Outlook in Selective Oxidation. Selective Oxidation by Heterogeneous Catalysis, 1st ed.; Springer US: New York, NY, USA; pp 1-24. doi:10.1007/978-1-4615-4175-2_1

2. Adolfsson, $\mathrm{H}$. Transition Metal-Catalyzed Epoxidation of Alkenes. In Modern Oxidation Methods; Bäckvall, J.-E., Ed.; Wiley-VCH: Weinheim, Germany, 2004; pp 21-49. doi:10.1002/3527603689.ch2

3. Dubois, G.; Murphy, A.; Stack, T. D. P. Org. Lett. 2003, 5, 2469-2472. doi:10.1021/ol0347085

4. Garcia-Bosch, I.; Ribas, X.; Costas, M. Adv. Synth. Catal. 2009, 351, 348-352. doi:10.1002/adsc.200800650

5. Duncan, D. C.; Chambers, R. C.; Hecht, E.; Hill, C. L. J. Am. Chem. Soc. 1995, 117, 681-691. doi:10.1021/ja00107a012

6. Collman, J. P.; Wang, Z.; Straumanis, A.; Quelquejeu, M.; Rose, E. J. Am. Chem. Soc. 1999, 121, 460-461. doi:10.1021/ja9818699

7. Tian, H.; She, X.; Xu, J.; Shi, Y. Org. Lett. 2001, 3, 1929-1931. doi:10.1021/ol010066e

8. White, M. C.; Doyle, A. G.; Jacobsen, E. N. J. Am. Chem. Soc. 2001, 123, 7194-7195. doi:10.1021/ja015884g

9. Zuwei, X.; Ning, Z.; Yu, S.; Kunlan, L. Science 2001, 292, 1139-1141. doi:10.1126/science.292.5519.1139

10. Moschona, F.; Savvopoulou, I.; Tsitopoulou, M.; Tataraki, D.; Rassias, G. Catalysts 2020, 10, 1117. doi:10.3390/catal10101117

11. Sharma, A. S.; Sharma, V. S.; Kaur, H.; Varma, R. S. Green Chem. 2020, 22, 5902-5936. doi:10.1039/d0gc01927e

12. Yan, W.; Wang, J.; Ding, J.; Sun, P.; Zhang, S.; Shen, J.; Jin, X. Dalton Trans. 2019, 48, 16827-16843. doi:10.1039/c9dt03456k

13. Bloch, R.; Abecassis, J.; Hassan, D. J. Org. Chem. 1985, 50, 1544-1545. doi:10.1021/jo00209a040

14. Lee, S. H.; Xu, L.; Park, B. K.; Mironov, Y. V.; Kim, S. H.; Song, Y. J.; Kim, C.; Kim, Y.; Kim, S.-J. Chem. - Eur. J. 2010, 16, 4678-4685. doi:10.1002/chem.200903135

15. Kazemnejadi, M.; Mahmoudi, B.; Sharafi, Z.; Nasseri, M. A.; Allahresani, A.; Esmaeilpour, M. J. Organomet. Chem. 2019, 896, 59-69. doi:10.1016/j.jorganchem.2019.05.030

16. Teo, P. S.; Lim, H. N.; Huang, N. M.; Chia, C. H.; Harrison, I. Ceram. Int. 2012, 38, 6411-6416. doi:10.1016/j.ceramint.2012.05.014 
17. Cao, H.; Zhu, B.; Yang, Y.; Xu, L.; Yu, L.; Xu, Q. Chin. J. Catal. 2018, 39, 899-907. doi:10.1016/s1872-2067(18)63050-5

18. Qian, L.; Wang, Z.; Beletskiy, E. V.; Liu, J.; dos Santos, H. J.; Li, T.; Rangel, M. d. C.; Kung, M. C.; Kung, H. H. Nat. Commun. 2017, 8, 14881. doi:10.1038/ncomms 14881

19. Gupta, U. N.; Dummer, N. F.; Pattisson, S.; Jenkins, R. L.; Knight, D. W.; Bethell, D.; Hutchings, G. J. Catal. Lett. 2015, 145 , 689-696. doi:10.1007/s10562-014-1425-z

20. Li, Z.; Gao, L.; Zhu, X.; Ma, W.; Feng, X.; Zhong, Q. ChemCatChem 2019, 11, 5116-5123. doi:10.1002/cctc.201900845

21. Zhao, Y.; Guo, Y.; Wang, X.; Zhang, X. J. Mater. Sci. 2020, 55, 2006-2017. doi:10.1007/s10853-019-04093-4

22. Thornburg, N. E.; Thompson, A. B.; Notestein, J. M. ACS Catal. 2015, 5, 5077-5088. doi:10.1021/acscatal.5b01105

23. Thornburg, N. E.; Nauert, S. L.; Thompson, A. B.; Notestein, J. M. ACS Catal. 2016, 6, 6124-6134. doi:10.1021/acscatal.6b01796

24. Joergensen, K. A. Chem. Rev. 1989, 89, 431-458. doi:10.1021/cr00093a001

25. Lane, B. S.; Burgess, K. Chem. Rev. 2003, 103, 2457-2474. doi:10.1021/cr020471z

26. Nasrallah, A.; Grelier, G.; Lapuh, M. I.; Duran, F. J.; Darses, B.; Dauban, P. Eur. J. Org. Chem. 2018, 5836-5842. doi:10.1002/ejoc.201800306

27. Blanckenberg, A.; Malgas-Enus, R. Catal. Rev.: Sci. Eng. 2019, 61, 27-83. doi:10.1080/01614940.2018.1492503

28. Gottuso, A.; Köckritz, A.; Saladino, M. L.; Armetta, F.; De Pasquale, C.; Nasillo, G.; Parrino, F. J. Catal. 2020, 391, 202-211. doi:10.1016/j.jcat.2020.08.025

29. Hyun, M. Y.; Kim, S. H.; Song, Y. J.; Lee, H. G.; Jo, Y. D.; Kim, J. H.; Hwang, I. H.; Noh, J. Y.; Kang, J.; Kim, C. J. Org. Chem. 2012, 77, 7307-7312. doi:10.1021/j03009963

30. Deng, Q.; Liu, Y.; Chen, L.; Xu, M.; Naowarojna, N.; Lee, N.; Chen, L.; Zhu, D.; Hong, X.; Deng, Z.; Liu, P.; Zhao, C. Org. Lett. 2019, 21, 7592-7596. doi:10.1021/acs.orglett.9b02872

31. Buranaprasertsuk, P.; Tangsakol, Y.; Chavasiri, W. Catal. Commun. 2007, 8, 310-314. doi:10.1016/j.catcom.2006.06.022

32. Shit, S.; Saha, D.; Saha, D.; Guru Row, T. N.; Rizzoli, C. Inorg. Chim. Acta 2014, 415, 103-110. doi:10.1016/j.ica.2014.02.036

33. Jiang, J.; Chen, H.-Y.; Zhou, X.-T.; Chen, Y.-J.; Xue, C.; Ji, H.-B. ACS Omega 2020, 5, 4890-4899. doi:10.1021/acsomega.9b03714

34. Tang, Q.; Wang, Y.; Liang, J.; Wang, P.; Zhang, Q.; Wan, H. Chem. Commun. 2004, 440-441. doi:10.1039/b314864e

35. Gao, J.; Bai, L.; Zhang, Q.; Li, Y.; Rakesh, G.; Lee, J.-M.; Yang, Y.; Zhang, Q. Dalton Trans. 2014, 43, 2559-2565. doi:10.1039/c3dt52562g

36. Yu, G.; Sun, J.; Muhammad, F.; Wang, P.; Zhu, G. RSC Adv. 2014, 4, 38804-38811. doi:10.1039/c4ra03746d

37. Sebastian, J.; Jinka, K. M.; Jasra, R. V. J. Catal. 2006, 244, 208-218. doi:10.1016/j.jcat.2006.09.005

38. Weerakkody, C.; Biswas, S.; Song, W.; He, J.; Wasalathanthri, N.; Dissanayake, S.; Kriz, D. A.; Dutta, B.; Suib, S. L. Appl. Catal., B 2018, 221, 681-690. doi:10.1016/j.apcatb.2017.09.053

39. Opre, Z.; Mallat, T.; Baiker, A. J. Catal. 2007, 245, 482-486. doi:10.1016/j.jcat.2006.11.018

40. Beier, M. J.; Kleist, W.; Wharmby, M. T.; Kissner, R.; Kimmerle, B.; Wright, P. A.; Grunwaldt, J.-D.; Baiker, A. Chem. - Eur. J. 2012, 18, 887-898. doi:10.1002/chem.201101223

41. Li, B.; Jin, X.; Zhu, Y.; Chen, L.; Zhang, Z.; Wang, X. Inorg. Chim. Acta 2014, 419, 66-72. doi:10.1016/j.ica.2014.05.006
42. Engel, R. V.; Alsaiari, R.; Nowicka, E.; Miedziak, P. J.; Kondrat, S. A.; Morgan, D. J.; Edwards, J. K.; Hutchings, G. J. Catal. Today 2019, 333, 154-160. doi:10.1016/j.cattod.2018.09.005

43. Madadi, S.; Charbonneau, L.; Bergeron, J.-Y.; Kaliaguine, S. Appl. Catal., B 2020, 260, 118049. doi:10.1016/j.apcatb.2019.118049

44. Mekrattanachai, P.; Cao, C.; Li, Z.; Li, H.; Song, W. RSC Adv. 2018, 8 , 37303-37306. doi:10.1039/c8ra07168c

45. Buxaderas, E.; Graziano Mayer, M.; Volpe, M. A.; Radivoy, G. Synthesis 2017, 49, 1387-1393. doi:10.1055/s-0036-1588628

46. Nador, F.; Moglie, Y.; Vitale, C.; Yus, M.; Alonso, F.; Radivoy, G. Tetrahedron 2010, 66, 4318-4325. doi:10.1016/j.tet.2010.04.026

47. Gutiérrez, V.; Nador, F.; Radivoy, G.; Volpe, M. A. Appl. Catal., A 2013, 464-465, 109-115. doi:10.1016/j.apcata.2013.05.028

48. Buxaderas, E.; Volpe, M. A.; Radivoy, G. Synthesis 2019, 51, 1466-1472. doi:10.1055/s-0037-1610318

49. Nador, F.; Volpe, M. A.; Alonso, F.; Feldhoff, A.; Kirschning, A.; Radivoy, G. Appl. Catal., A 2013, 455, 39-45. doi:10.1016/j.apcata.2013.01.023

50. Gutiérrez, V.; Mascaró, E.; Alonso, F.; Moglie, Y.; Radivoy, G. RSC Adv. 2015, 5, 65739-65744. doi:10.1039/c5ra10223e

51. Alonso, F.; Moglie, Y.; Radivoy, G. Acc. Chem. Res. 2015, 48, 2516-2528. doi:10.1021/acs.accounts.5b00293

52. Moglie, Y.; Buxaderas, E.; Mancini, A.; Alonso, F.; Radivoy, G. ChemCatChem 2019, 11, 1487-1494. doi:10.1002/cctc.201801858

53. Cortes-Concepcion, J. A.; Williams, C. T.; Amiridis, M. D. Catal. Commun. 2011, 16, 198-204. doi:10.1016/j.catcom.2011.09.033

54. Biesinger, M. C.; Payne, B. P.; Grosvenor, A. P.; Lau, L. W. M.; Gerson, A. R.; Smart, R. S. C. Appl. Surf. Sci. 2011, 257, 2717-2730. doi:10.1016/j.apsusc.2010.10.051

55. Ghosh, B. K.; Moitra, D.; Chandel, M.; Patra, M. K.; Vadera, S. R.; Ghosh, N. N. Catal. Lett. 2017, 147, 1061-1076. doi:10.1007/s10562-017-1993-9

56. Pardeshi, S. K.; Pawar, R. Y. J. Mol. Catal. A: Chem. 2011, 334 , 35-43. doi:10.1016/j.molcata.2010.10.020

57. Nador, F.; Volpe, M. A.; Alonso, F.; Radivoy, G. Tetrahedron 2014, 70 , 6082-6087. doi:10.1016/j.tet.2014.04.003

\section{License and Terms}

This is an Open Access article under the terms of the Creative Commons Attribution License (https://creativecommons.org/licenses/by/4.0). Please note that the reuse, redistribution and reproduction in particular requires that the author(s) and source are credited and that individual graphics may be subject to special legal provisions.

The license is subject to the Beilstein Journal of Organic Chemistry terms and conditions: (https://www.beilstein-journals.org/bjoc/terms)

The definitive version of this article is the electronic one which can be found at: https://doi.org/10.3762/bjoc. 17.46 